\title{
Changes of antithroglobulin antibody in children with congenital hypothyroidism
}

\author{
Eun Mi Cho, MD, \\ Uk Hyun Kim, MD, \\ Byung Ho Choi, MD, \\ Cheol Woo Ko, MD, PhD \\ Department of Pediatrcs, Kyungpook \\ National University Children's \\ Hospital, Daegu, Republic of Korea
}

\begin{abstract}
Purpose: It has been reported that antithroglobulin (anti-TG) antibody is increased in the sera of both children with transient congenital hypothyroidism and their mothers. And transplacental transport of thyroid autoantibody was proposed as the pathogenesis of transient congenital hypothyroidism. However this is not known in nontransient congenital hypothyroidism. This study was done to see changes of antiTG antibody in children with nontransient congenital hypothyroidism.

Methods: Study patients consisted of 60 patients diagnosed as congenital hypothyroidism in the Department of Pediatrics, Kyungpook National University Children's Hospital, Daegu, Republic of Korea between January 2010 and March 2013. Healthy control were 45 children showing normal thyroid function. Anti-TG antibody and various laboratory tests were analyzed retrospectively, and compared in both children with congenital hypothyroidism and controls.

Results: Anti-TG antibody was significantly higher in children with congenital hypothyroidism compared to healthy controls, $119.4 \pm 34.7 \mathrm{U} / \mathrm{mL}$ versus $80.6 \pm 19.6 \mathrm{U} /$ $\mathrm{mL}$, respectively $(P<0.001)$. There was no significant difference of anti-TG antibody in gender and age.

Conclusion: We observed a significant increase of anti-TG antibody in children with nontransient congenital hypothyroidism compared to healthy controls. Further study focusing pathogenetic role of anti-TG antibody in nontransient congenital hypothyroidism is necessary. Furthermore, the clinical significance in the course of congenital hypothyroidism need to be known.
\end{abstract}

Keywords: Congenital hypothyroidism, Autoantibodies, Anti-thyroglobulin antibody
Received: 22 August, 2013

Revised: 16 September, 2013

Accepted: 10 October, 2013

Address for correspondence:

Cheol Woo Ko, MD, PhD

Department of Pediatrics,

Kyungpook National University

Medical Center, Kyungpook

National University School of

Medicine, 130 Dongdeok-ro, Jung-

gu, Daegu 700-721, Republic of

Korea

Tel: +82-53-420-5704

Fax: +82-53-425-6683

E-mail:cwko@knu.ac.kr

\section{Introduction}

Congenital hypothyroidism is the most common congenital endocrine disorder in childhood, with an incidence of 1:4,000 live births ${ }^{1)}$. Distinctive symptoms are often not manifested in many cases and this leads to delay in diagnosis and treatment. Patients with congenital hypothyroidism often suffer from sequela including delayed bone maturation, growth and development, intelligence disorder, motor disorder, speech impairment, and others $^{2)}$. Late treatment during infancy, in particular, could generate irreversible brain injury and neurological sequela due to delayed development in the central nervous system ${ }^{2,3)}$. A leading form of acquired hypothyroidism is Hashimoto disease and its major clinical symptom is thyroid goiter without tenderness. The pathogenesis of Hashimoto disease is known as abnormal activation of T lymphocyte and the destruction of thyroid tissues caused by antiperoxidase antibody (anti-TPO Ab), thyroid autoimmune antibody, or antithyroglobulin antibody (anti-TG Ab) ${ }^{4}$.

The authors of this study incidentally experienced an higher level of anti-TG Ab in children with nontransient congenital hypothyroidism during their followed up workups including anti-TG Ab at outpatient clinic. The aim of this study is to compare children with healthy 
control group to verify an increase of anti-TG Ab in children with nontransient congenital hypothyroidism.

\section{Materials and methods}

Study patients consisted of patients diagnosed as congenital hypothyroidism outpatiently in the Department of Pediatrics, Kyungpook National University Children's Hospital from January 2010 to March 2013. Subjects were retrospectively examined with sex, age, $\mathrm{T}_{3}$, free $\mathrm{T}_{4}$, thyroid stimulating hormone (TSH) and anti-TG Ab. The causes of congenital hypothyroidism were classified with thyroid ultrasonography and thyroid scan. Control group comprised 45 patients with normal thyroid function without auto-immune disorders by taking age and sex of patient group with congenital hypothyroidism into consideration. Children diagnosed at the age less than 2 years old was excluded from study patients to differentiate transient congenital hypothyroidism and nontransient congenital hypothyroidism. Hypothyroidism was defined by low levels of $\mathrm{T}_{4}$ or free $\mathrm{T}_{4}$ by age, and an elevated TSH level ${ }^{5)}$. Analysis was performed using Brahms TSH 1 radioimmunoassay (RIA) kit (Thermo Fisher Scientific, Bremen, Germany) for TSH, RIAgnost $\mathrm{T}_{3}$ kit (Cisbio Bioassays, Codolet, France) for $\mathrm{T}_{3}, \mathrm{fT}_{4}$ RIA kit (Beckman Coulter, Brea, CA, USA) for free $\mathrm{T}_{4}$, and Thyroglobulin IRMA kit (Cisbio Bioassay, Codolet, France) for anti-TG Ab. Statistical analysis was conducted using PASW ver. 18.0.0 (IBM Co., Armonk, NY, USA) and $P$-values of less than 0.05 were considered statistically significant.

\section{Results}

A total of 60 children with congenital hypothyroidism comprised 26 boys and 34 girls with the ratio of boys to girls of 1:1.3 and mean age was $8.4 \pm 3.8$ years. Control group involved a total of 45 patients comprising 30 boys and 15 girls with the ratio of boys to girls of 1:0.5. Mean age was 3.1 \pm 3.3 years (Table 1). Among those patients, the causes of congenital hypothyroidism were identified in 44 out of 60 subjects. The causes were thyroid dyshormonogenesis in 26 patients (59\%), thyroid dysgenesis in 13 patients (30\%), thyroid agenesis in 4 patients (9\%), and

Table 1. Clinical manifestations and laboratory findings of study patients and controls

\begin{tabular}{lccr}
\hline Variable & $\begin{array}{c}\text { Congenital } \\
\text { hypothyroidism }\end{array}$ & Controls & P-value \\
\hline Number & 60 & 45 & \\
Male : female ratio & $1: 1.3$ & $1: 0.5$ & \\
Age $(\mathrm{yr})$ & $8.4 \pm 3.8$ & $6.5 \pm 4.2$ & \\
$\mathrm{~T}_{3}(\mathrm{ng} / \mathrm{mL})$ & $1.4 \pm 1.0$ & $1.3 \pm 0.5$ & 0.930 \\
Free $\mathrm{T}_{4}(\mathrm{ng} / \mathrm{dL})$ & $0.8 \pm 0.5$ & $1.3 \pm 0.2$ & $<0.001$ \\
$\mathrm{TSH}_{(\mu \mathrm{Ul} / \mathrm{mL})}$ & $63.6 \pm 32.3$ & $2.9 \pm 2.3$ & $<0.001$ \\
Anti-TG antibody & $119.4 \pm 34.7$ & $80.6 \pm 19.6$ & $<0.001$ \\
$(\mathrm{U} / \mathrm{mL})$ & & & \\
\hline
\end{tabular}

Values are presented as mean \pm standard deviation.

TSH, thyroid stimulating hormone; Anti-TG, antithroglobulin. ectopic thyroid in a 1 patient $(2 \%)$. The result of thyroid function test in the initial diagnosis of nontransient hypothyroidism children is shown in Table 1 . Their serum $\mathrm{T}_{3}$ level $(\mathrm{ng} / \mathrm{mL})$ was $1.4 \pm 1.0$, showing no statistically significant difference compared to $1.3 \pm 0.5$ of control group $(P=0.930)$. Serum free $\mathrm{T}_{4}$ level (ng/ dL) was $0.8 \pm 0.5$ in congenital hypothyroidism group, and was significantly lower compared to $1.3 \pm 0.2$ of control group $(P$ $<0.001)$. TSH level $(\mu \mathrm{IU} / \mathrm{mL})$ was $63.6 \pm 32.3$ in congenital hypothyroidism group, and was statistically significant higher compared to $2.9 \pm 2.3$ of control group $(P<0.001)$ (Table 1$)$. Among 60 patients with congenital hypothyroidism, anti-TG Ab level $(\mathrm{U} / \mathrm{mL})$ was $119.4 \pm 34.7$, and was significant higher compared to $80.6 \pm 19.6$ of control group $(P<0.001)$ (Table 1$)$.

Anti-TG Ab level $(\mathrm{U} / \mathrm{mL})$ was examined by sex in chlidren with congenital hypothyroidism, anti-TG Ab levels were $114.5 \pm 31.4$ in boys and $121.3 \pm 35.8$ in girls, showing no statistically significant difference. There was no statistically significant difference in patient group with congenital hypothyroidism by age (Fig. 1).

\section{Discussion}

Thyroid hormone plays crucial role in development and differentiation of the central nervous system, physical growth and pubertal development, dental and skeletal growth, metabolism, and functional maintenance of organs ${ }^{6}$. Congenital hypothyroidism is classified as the most common endocrine disorder in childhood showing the deficiency of thyroid hormone from the birth with an incidence of $1 / 4,000$ newborns according to the screening test of Fisher ${ }^{1)}$. The major causes of congenital hypothyroidism are thyroid dysgenesis or biosynthetic defects of thyroid hormone ${ }^{7,8)}$. Congenital hypothyroidism is divided into nontransient or transient according to duration of illness. Thyroid function is known to recover several months to years after birth in

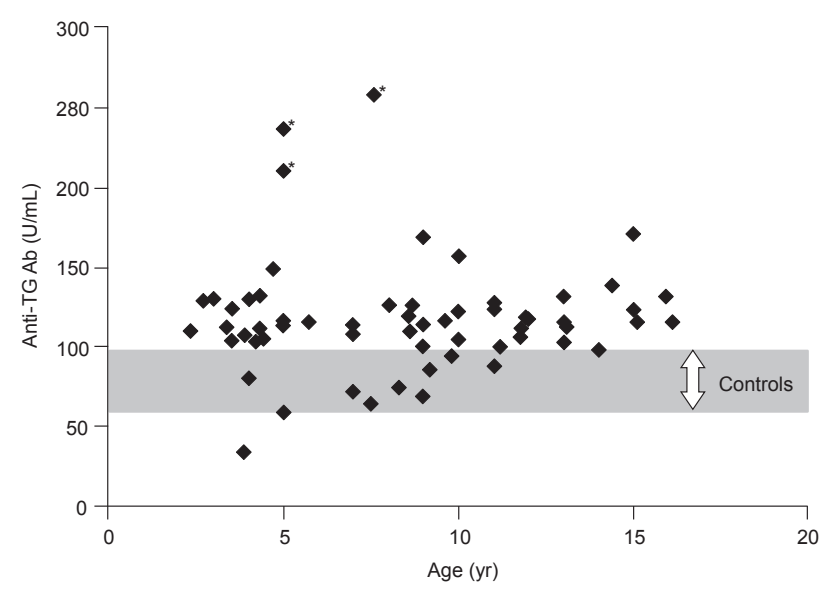

Fig. 1. Distributions of antithyroglobulin antibody (anti-TG Ab) in children with congenital hypothyroidism and controls. Translucent area indicates range of antiTG Ab titer in controls. The cause of congenital hypothyroidism in patients with 3 highest titers was thyroid agenesis $\left({ }^{*}\right)$. 
transient hypothyroidism ${ }^{8)}$. Distinctive symptoms are often not presented in many cases and this leads to delay in diagnosis and treatment ${ }^{9,10)}$. Late treatment during infancy, in particular, could incur irreversible brain injury and neurological sequela due to delayed development of central nervous system ${ }^{2,3)}$. The newborn screening for congenital hypothyroidism was first performed in Quebec city, Canada and Pittsburg, the United States in 1972, and the diagnosis rate of congenital hypothyroidism has almost doubled $^{11)}$. Republic of Korea has conducted the newborn screening for congenital hypothyroidism from the early 1990 's ${ }^{12}$.

Leading acquired thyroid disorders are Graves disease and Hashimoto disease. Significant auto-antibodies are anti-TPO $\mathrm{Ab}$, anti-TG Ab, anti-TSH receptor antibody (anti-TSHR Ab), and others in acquired thyroid disorders. Among those, antiTPO Ab and anti-TG Ab take very crucial role in diagnosing Graves disease and Hashimoto disease ${ }^{13)}$. Moreover, those autoantibodies may increase in autoimmune diseases including systemic lupus erythematosus or rheumatoid arthritis, in addition to thyroid disorders ${ }^{14)}$. Thyroglobulin is a $670 \mathrm{kDa}$ protein composed of 2,768 amino acids, and known as a clinically useful indicator in autoimmune thyroid disorders and thyroid cancer. And anti-TG Ab could be showed in about $11 \%$ of normal individuals ${ }^{15)}$. The authors of this study was able to identify a significant increase of anti-TG Ab in patient group with nontransient congenital hypothyroidism which is not acquired thyroid disorders compared to healthy control group. In the past, the transplacental movement of maternal anti-thyroid auto-antibodies had been suggested as the cause of congenital hypothyroidism as hypothesis. Bona et al. ${ }^{16)}$ performed screening test of anti-TG Ab, antimicrosomal antibody, and TSH blocking antibody (TSH-blocking Ab) in 18 newborns with congenital hypothyroidism and their 14 mothers. Among those, both antimicrosomal $\mathrm{Ab}$ and anti$\mathrm{TG} \mathrm{Ab}$ increased in 5\% of all newborns and their mothers. In addition, TSH-blocking $\mathrm{Ab}$ increased in a mother and her newborn. Authors were interpreted the result of this study by the movement of IgG from mothers to newborns through placenta, and it influenced the thyroid development of infant. Toublanc et al. ${ }^{17)}$ performed screening test for thyroid auto-antibodies in 42 newborns with congenital hypothyroidism and their mothers. Among those, TSH binding inhibitor antibody increased in $38 \%$ of newborns. However, there was no association with the results of their mothers. Antibody-dependant cell mediated cytotoxicity and thyroid growth immunoglobulin block accounted for $24 \%$ of all patients, respectively. The association with maternal results reportedly accounted for $90 \%$ in the former one and $84 \%$ in the latter one. Ordookhani et al. ${ }^{18)}$ tested for thyroid hormone, TSHR Ab, anti-TPO Ab, and anti-TG Ab in mothers and their newborns with transient hypothyroidism. Newborns with hypothyroidism were treated thyroid hormone orally and showed normal thyroid function three years after gradual suspension of medication administration. Among 35,067 newborns conducted with screening test, 6 newborns were confirmed with transient hypothyroidism, and anti-TG Ab was positive in 4 out of 6 subjects. In control group, anti-TG Ab was positive only in 6 out of 106 subjects. Anti-TG Ab level was significantly higher in patient group than control group. Anti$\mathrm{TPO} \mathrm{Ab}$ was found to be negative in all subjects in transient hypothyroidism group. Sutherland et al. ${ }^{19)}$ and Goldsmith et al. ${ }^{20)}$ reported that pregnant women with autoimmune hypothyroidism could generate hypothyroidism in newborns due to the transplacental movement of auto-antibodies.

This study observed that anti-TG Ab significantly increased in patient group with nontransient congenital hypothyroidism unlike transient hypothyroidism compared to control group. Significant increases were shown in anti-TG Ab levels in all disorders of thyroid dysgenesis, thyroid dyshormonogenesis and thyroid agenesis regardless of different causes of congenital hypothyroidism. We think our study is a pilot one showing increased anti-TG Ab titer in nontransient congenital hypothyroidism, because we could not find any literature on the change of anti-TG Ab in children with nontransient congenital hypothyroidism. The hypothesis of higher anti-TG Ab titer in children with nontransient congenital hypothyroidism is that antigenicity related to thyroid tissue or proteins would be associated with the pathogenesis of nontransient congenital hypothyroidism. Three study patients showing the highest titers of anti-TG Ab has agenetic thyroid (Fig. 1). It can be said that higher titers of anti-TG Ab in children with thyroid agenesis may support our hypothesis in part.

There are some limitations in the study. Our study showed the most common cause of congenital hypothyroidism was dyshormonogenesis rather than dysplasia of thyroid gland. We thought this is because of small number of study patients and/ or limitation of one institute survey. And we did not analyze changes of anti-TG Ab in series. Another limitation was that the level of thyroid auto-antibodies was not assessed. In order to differentiate transient congenital hypothyroidism and nontransient congenital hypothyroidism, we excluded patients under 2 years of age from study patients. Anti-TG Ab was significantly higher in patients with nontransient congenital hypothyroidism instead of transient hypothyroidism. Therefore, additional studies are thought to be necessary to survey the relationship between thyroid autoimmune antibodies such as anti-TG Ab and the incidence of nontransient congenital hypothyroidism. Furthermore, more studies are thought to be crucial to investigate anti-TG Ab and clinical progression.

In conclusion, anti-TG Ab significantly increased in chlidren with nontransient congenital hypothyroidism. Further studies are necessary to investigate the effect of thyroid autoimmune antibodies on the incidence and clinical progress of congenital hypothyroidism.

\section{Conflict of interest}

No potential conflict of interest relevant to this article was reported. 


\section{References}

1. Fisher DA. Second International Conference on Neonatal Thyroid Screening: progress report. J Pediatr 1983;102:6534.

2. Oyarzabal M, Chueca M, Elso J, Sola A; Comision de Tiroides de la SEEP. Neonatal screening of congenital Hypothyroidism: result of the Navarra program. An Sist Sanit Navar 1998;21:331-9.

3. Macfaul R, Dorner S, Brett EM, Grant DB. Neurological abnormalities in patients treated for hypothyroidism from early life. Arch Dis Child 1978;53:611-9.

4. Brix TH, Kyvik KO, Hegedus L. What is the evidence of genetic factors in the etiology of Graves' disease? A brief review. Thyroid 1998;8:727-34.

5. Kliegman RM, Stanton BF, St. Geme JW, Schor NF, Behrman RE. Nelson textbook of pediatrics. 19th ed. Philadelphia: Elsevier, 2011;1899-900.

6. Sari E, Karaoglu A, Yesilkaya E. Hashimoto's thyroiditis in children and adolescents. Rijeka (HR): InTech Open Access Publisher, 2011;27-40.

7. Hanukoglu A, Perlman K, Shamis I, Brnjac L, Rovet J, Daneman D. Relationship of etiology to treatment in congenital hypothyroidism. J Clin Endocrinol Metab 2001;86:186-91.

8. Rastogi MV, LaFranchi SH. Congenital hypothyroidism. Orphanet J Rare Dis 2010;5:17.

9. LaFranchi SH. Hypothyroidism. Pediatr Clin North Am 1979;26:33-51.

10. Gravdal JA, Meenan A, Dyson AE. Congenital hypothyroidism. J Fam Pract 1989;29:47-50.

11. Verkerk PH, Buitendijk SE, Verloove-Vanhorick SP. Congenital hypothyroidism screening and the cutoff for thyrotropin measurement: recommendations from The
Netherlands. Am J Public Health 1993;83:868-71.

12. Lee JM, Choi TY, Lee DW, Lee DH. Recheck rate, recall rate and reference range of the neonatal screening test for congenital hypothyroidism. J Clin Pathol Qual Control 2001;23:215-20.

13. Sinclair D. Clinical and laboratory aspects of thyroid autoantibodies. Ann Clin Biochem 2006;43(Pt 3):173-83.

14. Konstadoulakis MM, Kroubouzos G, Tosca A, Piperingos G, Marafelia P, Konstadoulakis M, et al. Thyroid autoantibodies in the subsets of lupus erythematosus: correlation with other autoantibodies and thyroid function. Thyroidology 1993;5:1-7.

15. Sinclair D. Analytical aspects of thyroid antibodies estimation. Autoimmunity 2008;41:46-54.

16. Bona G, Chiovato L, Campra D, Paniccia P, Zaffaroni M, Costa L, et al. Thyroid autoimmunity: really an important cause of sporadic congenital hypothyroidism? Panminerva Med 1991;33:145-51.

17. Toublanc JE, Gruters A, Bogner U, Fulla Y, Dugue MA. Study of antibody-dependent cell mediated cytotoxicity and thyroid growth blocking antibodies in congenital hypothyroidism. Arch Fr Pediatr 1991;48:89-94.

18. Ordookhani A, Mirmiran P, Walfish PG, Azizi F. Transient neonatal hypothyroidism is associated with elevated serum anti-thyroglobulin antibody levels in newborns and their mothers. J Pediatr 2007;150:315-7,317.e2.

19. Sutherland JM, Esselborn VM, Burket RL, Skillman TB, Benson JT. Familial nongoitrous cretinism apparently due to maternal antithyroid antibody: report of a family. N Engl J Med 1960;263:336-41.

20. Goldsmith RE, McAdams AJ, Larsen PR, McKenzie M, Hess E. Familial autoimmune thyroiditis: maternal-fetal relationship and the role of generalized autoimmunity. J Clin Endocrinol Metab 1973;37:265-75. 